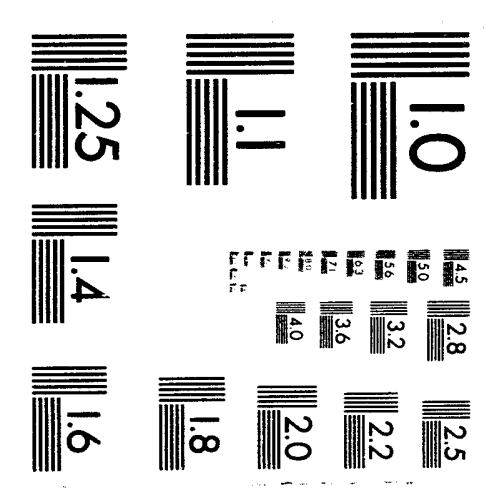



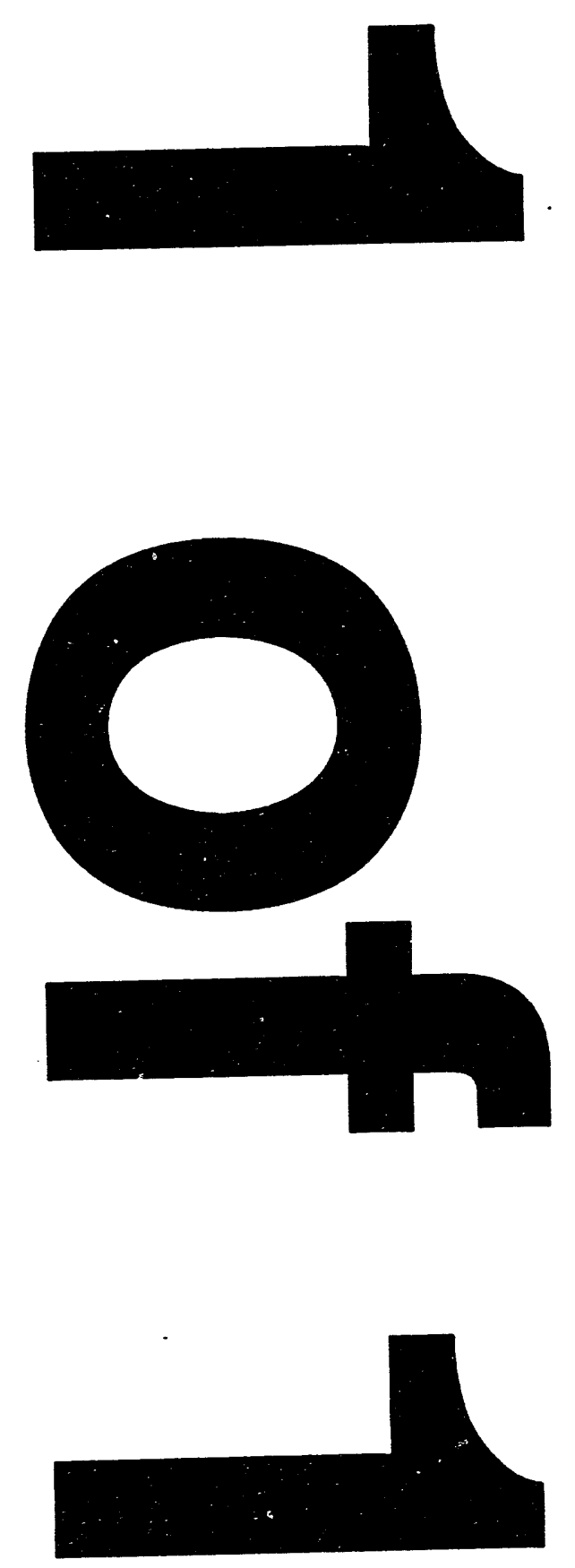


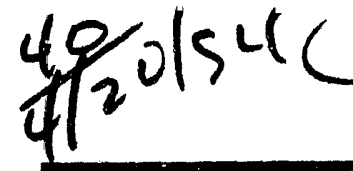

PPPL-2981

PPPL-2981

UC-420

DOPPLER-SHIFTED NEUTRAL BEAM LINE SHAPE AND BEAM TRANSMISSION

BY

J.H. KAMPERSCHROER, L.R. GRISHAM, N. KOKATNUR, ET AL.

APRIL, 1994

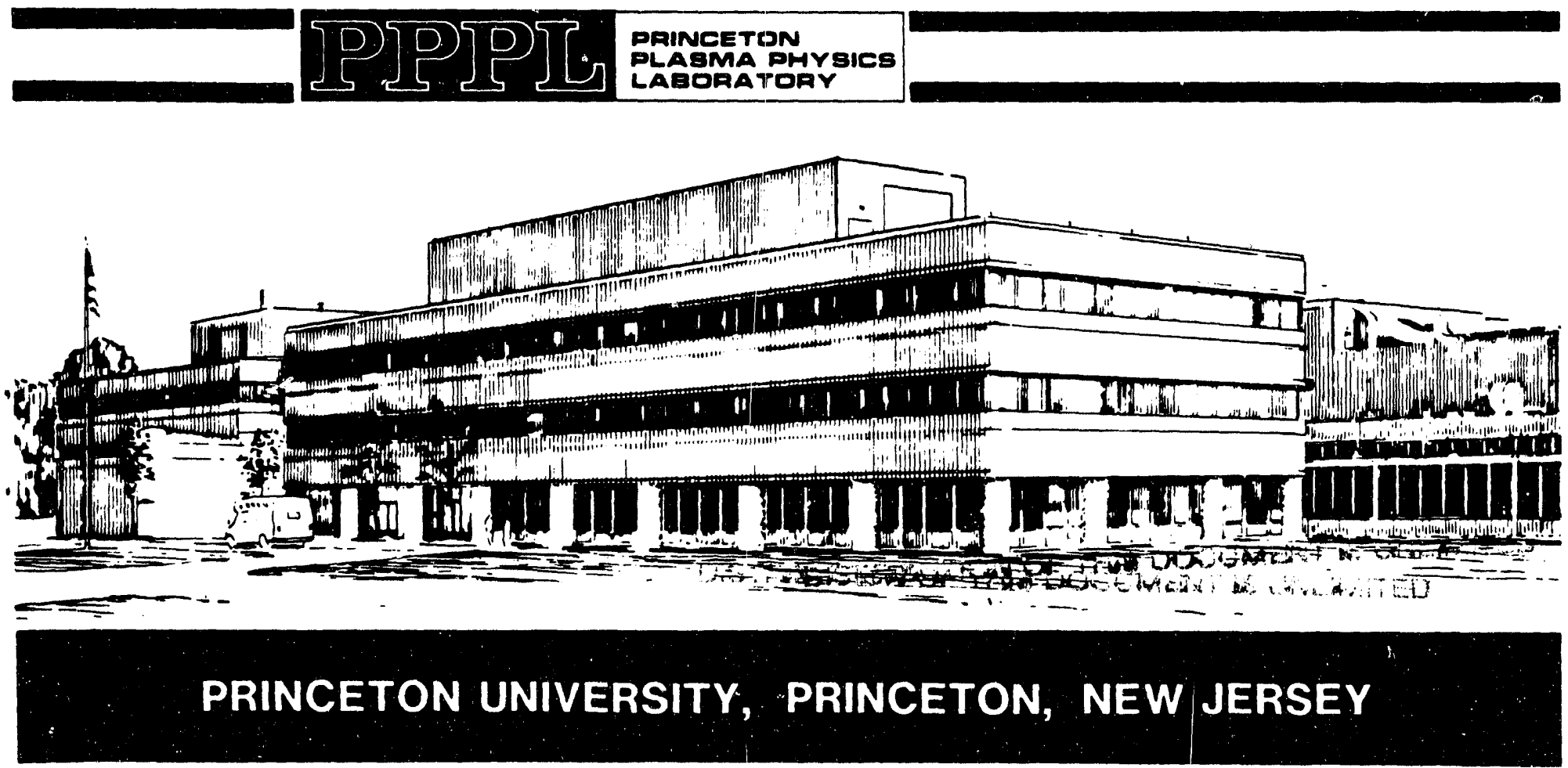




\section{NOTICE}

This report was prepared as an account of work sponsored by an agency of the United States Government. Neither the United States Government nor any agency thereof, nor any of their employees, makes any warranty, express or implied, or assumes any legal liability or responsibility for the accuracy, completeness, or usefulness of any information, apparatus, product, or process disclosed, or represents that its use would not infringe privately owned rights. Reference herein to any specific commercial produce, procsss, or service by trade name, trademark, manufacturer, or otherwise, does not necessarily constitute or imply its endorsement, recommendation, or favoring by the United States Government or any agency thereof. The views and opinions of authors expressed herein do not necessarily state or reflect those of the United States Government or any agency thereof.

\section{NOTICE}

This report has been reproduced from the best available copy.

Available in paper copy and microfiche.

Number of pages in this report: 36

DOE and DOE contractors can obtain copies of this report from:

Office of Scientific and Technical Information P.O. Box 62

Oak Ridge, TN 37831 ;

(615) $576-8401$.

This report is publicly available from the:

National Technical Information Service

Department of Commerce

5285 Port Royal Road

Springfield, Virginia 22161

(703) $487-4650$ 


\title{
Doppler-Shifted Neutral Beam Line Shape and Beam Transmission
}

\author{
J. H. Kamperschroer, L. R. Grisham, N. Kokatnur, ${ }^{\dagger}$ L. J. Lagin, R. A. Newman, \\ T. E. O'Connor, T. N. Stevenson, and A. von Halle \\ Princeton Plasma Physics Laboratory, PO Box 451, Princeton, New Jersey 08543
}

\begin{abstract}
Analysis of Doppler-shifted Balmer- $\alpha$ line emission from the TFTR neutral beam injection systems has revealed that the line shape is well approximated by the sum of two Gaussians, or, alternatively, by a Lorentzian. For the sum of two Gaussians, the broad portion of the distribution contains $40 \%$ of the beam power and has a divergence five times that of the narrow part. Assuming a narrow 1/edivergence of $1.3^{\circ}$ (based on fits to the beam shape on the calorimeter), the broad part has a divergence of $6.9^{\circ}$. The entire line shape is also well approximated by a Lorentzian with a half-maximum divergence of $0.9^{\circ}$. Up to now, fusion neutral beam modelers have assumed a single Gaussian velocity distribution, at the extraction plane, in each direction perpendicular to beam propagation. This predicts a beam transmission efficiency from the ion source to the calorimeter of 97\% . Waterflow calorimetry data, however, yield a transmission efficiency of $\sim 75 \%$, a value in rough agreement with predictions of the Gaussian or Lorentzian models presented here. The broad wing of the two Gaussian distribution also accurately predicts the loss in the neutralizer. An average angle of incidence for beam loss at the exit of the neutralizer is $2.2^{\circ}$, rather than the $4.95^{\circ}$ subtended by the center of the ion source. This average angle of incidence, which is used in computing power densities on collimators, is shown to be a function of beam divergence.
\end{abstract}




\section{INTRODUCTION}

Tokamak Fusion Test Reactor (TFTR) neutral beams have reliably injected 24 MW of power for two seconds, and up to $34 \mathrm{MW}$ for shorter pulses, into high quality plasmas. ${ }^{1}$ Dissipation of a minute fraction of the extracted energy has resulted in damage to the collimators close to the ion source. Notwithstanding such difficulties, overall system availability has been $\sim 95 \%$.

Pulse lengths on neutral beam injection systems around the world have dramatically increased over the years. Presently they stand at five seconds for DIII-D ${ }^{2}$ (with consideration being given to further upgrades to $60 \mathrm{~s}$ ), ${ }^{3}$ ten seconds for ASDEX, ${ }^{4}$ TEXTOR, ${ }^{5}$ JT- $60,{ }^{6}$ and the Joint European Torus( JET), ${ }^{7,} 8$ twenty seconds for the JET test bed, and thirty seconds for the Lawrence Berkeley Laboratory (LBL) Neutral Beam Engineering Test Facility (NBETF), 10 (since decommissioned). Tore Supra has a goal of thirty seconds, ${ }^{11}$ thirty minute pulses at reduced power are anticipated for the Large Superconducting Helical Device (LSHD), ${ }^{12}$ and pulses of hundreds of hours are specified for the International Thermonuclear Experimental Reactor (ITER). ${ }^{13}, 14$ Consideration also is being given to increasing the pulse length of TFTR beamlines to $1000 \mathrm{~s}$ for use on its proposed successor, the Tokamak Physics Experiment (TPX). Operation at pulse lengths exceeding a few seconds necessitates a detailed knowledge of the beam shape to accurately predict power densities and design reliable collimators.

A prime concern is power dissipation close to the ion source. LBL found that $\sim 84 \%$ of the power extracted from their ion source was delivered to the NBETF target. ${ }^{15}$ Similar measurements at General Atomics ${ }^{16}$ and the Princeton Plasma Physics Laboratory ${ }^{17}$ yielded somewhat lower transmission efficiencies, 68-78\%. The majority of the loss was discovered to occur close to the ion source: $6.5 \%$ in the 
OMA box ${ }^{15}$ and $10 \%$ in the neutralizer, ${ }^{16}$ or, alternatively, $15 \%$ in the neutralizer and collimators combined. ${ }^{17} \mathrm{~A}$ clear understanding of these losses has been lacking.

Losses of this magnitude are not predicted by the prevailing model of beam transport, wherein it is assumed that the beam is extracted from uniform emitters having a Gaussian velocity distribution function. A convolution of such functions yields a beam shape given by the difference of error functions, ${ }^{18}$ with a near-field shape characterized by a central plateau with Gaussian-like wings. A fit to this function, from thermocouples embedded in the calorimeter, is used in the TFTR, and other, beamlines to determine the widths (divergences) of the velocity distribution function of the emitter. ${ }^{19}$ Computation of the distribution function from this thermal data requires a sophisticated non-linear least squares fit. Given typical $1 / \mathrm{e}$-divergences of $0.35^{\circ}$ and $1.5^{\circ}$, parallel and perpendicular to the grid rails, respectively, as measured this manner, a beam transmission efficiency from the ion source to the calorimeter of $>95 \%$ is predicted. A value that widely misses the measured $75 \%$ mark.

It has long been known that the velocity distribution function of neutral beams is non-Gaussian. Shapes of the Doppler-shifted $D \alpha$ lines emitted by the beam neutrals provide clear evidence of this fact. To compensate for this deviation from a pure Gaussian, computer programs developed by LBL to analyze the Dopplershifted neutral beam light emission use a modified Gaussian. A negative exponent of $2 \alpha$, where $\alpha$ is a fit parameter, is used rather than $2 .{ }^{19}$ While an improved fit to the data results compared to that of a simple Gaussian, the choice of this model was entirely empirical.

Other functions have been postulated but never exploited to ascertain their worthiness. Recently it was noted, in parallel with this work, that the line shapes 
from the Wendelstein 7-AS neutral beams are the sum of two Gaussians. ${ }^{20}$ The use of a more physical Lorentzian distribution has also been proposed. Another model has been suggested that places small Gaussians on either side of a larger Gaussian. ${ }^{21}$ This model introduces the added parameters of the relative amplitude, width, and location of the side Gaussians. Values for these new parameters were obtained through calorimetric measurements on a set of collimators located close to the ion source. ${ }^{21}$ Each of these new models yields a beam shape possessing the desired feature of highly divergent wings.

In lieu of implementing this latter multiple-Gaussian model, a simpler, more physical model, based on either the sum of two coincident Gaussians or a Lorentzian, has been developed. This model will be described and then employed to predict beam loss within the TFTR/TPX beamlines. Since the angles at which the incident particles strike the surface enter into the computation of power density, their effect is also examined.

\section{EXPERIMENTAL APPARATUS}

Figure 1 is an elevation view of a TFTR neutral beamline. ${ }^{22,23}$ The ion source, located at the extreme right in the figure, is the LBL-designed U. S. Common Long Pulse Ion Source (CLPIS), ${ }^{24}$ in which a beam is extracted from slots in a 12 cm (horizontal) by $43.7 \mathrm{~cm}$ (vertical) accelerator. ${ }^{15}$ Acceleration slots are between horizontal water cooled grid rails. Beam optics are poorer in the direction perpendicular to the grid rails than in the direction parallel to the grid rails. Upon leaving the ground grid of the accelerator, the beam enters the neutralizer, a $15 \mathrm{~cm}$ wide by $50 \mathrm{~cm}$ tall, $250 \mathrm{~cm}$ long, structure serving as a conduit for cold gas 
and beam particles. Charge-changing collisions here convert a large fraction of the incident ions into neutral atoms. One of the first sections of the neutralizer is a chamber equipped with viewing ports that permit spectroscopic analysis of the light emission. After the beam exits the neutralizer it enters the large neutral beam vacuum enclosure, passing in sequence: the deflection magnet, the calorimeter which can be lowered to intercept the beam, and then, if the calorimeter is retracted, into the duct connecting the beam box to the tokamak.

Spectroscopic analysis of the emission of excited beam atoms was pioneered by LBL. ${ }^{25}$ A system with two Optical Multichannel Analyzer (OMA) detectors has been employed on TFTR for many years. ${ }^{26}$ Light from a viewing port in the first section (OMA box) of the neutralizer is captured and sent to a spectrometer. The line-of-sight is such as to blue shift the $\mathrm{D} \alpha$ emission of the energetic neutrals relative to the unshifted $D \alpha$ line of the thermal neutralizer gas. The field of view, which is perpendicular to the grid rails, intersects the beam axis at a location $\sim 70$ $\mathrm{cm}$ downstream of the exit grid of the accelerator.

Generally, this diagnostic is used to measure the compo. 'ion of the beam. However, it can be used to measure beam divergence. ${ }^{19}, 27,28$ The vertical OMA line-of-sight provides a view of all beamlets. If emission from all beamlets are identical, the line shape yields the velocity distribution. Such a measure of the divergence is far simpler than deconvolving the sum of the distributions from many beamlets, as done with the thermal profile on the calorimeter.

Typical signal to noise ratios of OMA data are 30-100 to 1, sufficient to provide an accurate measure of the velocity distribution function. The close proximity of the OMA to the ion source allows measurement of the highly divergent wing of the distribution; diagnostics located further downstream ${ }^{29}$ can only measure the central portion of the distribution, since the relevant wings are lost in transport. 


\section{LEAST SQUARES FITS TO THE DATA}

Figure 2 displays a typical 500 channel OMA spectrum from a deuterium beam accelerated to $100 \mathrm{kV}$. Data are plotted as counts versus channel number, i.e., wavelength. Left to right, the first three lines are due to Doppler-shifted emission from full-energy $D^{0}$, half-energy $D^{0}$, and third-energy $D^{0}$. At the right, the large line is due to the unshifted $D \alpha$ emission from the thermal neutralizer gas. A small, isotopically shifted, $\mathrm{H} \alpha$ line appears just to the right of the unshifted $\mathrm{D} \alpha$ peak. The source of this $\mathrm{H} \alpha$ light is most likely water in the arc chamber coming from either a small water leak or humidity in adsorbed air. ${ }^{30}$ It is not usually present.

Data from channels $1-300$ are used in each of the fitting algorithms to be described. Prior to fitting, a linear background is subtracted from the data. This background is a straight line from the value at channel 1 to the value at channel 300. Such a subtraction removes most of the signal due to reflections (small in this case) and the signal attributed to partial energy atoms. The resultant data are independently fit to four separate distribution functions: a Gaussian

$$
f(\lambda)=\sum_{i=1}^{3} A_{i} e^{-\left(\frac{\lambda-\lambda_{0 i}}{\Delta \lambda_{i}}\right)^{2}}
$$

a modified Gaussian

$$
f(\lambda)=\sum_{i=1}^{3} A_{i} e^{-\left(\frac{\lambda-\lambda_{0 i}}{\Delta \lambda_{i}}\right)^{2 \alpha_{i}}}
$$


a sum of two Gaussians

$$
\mathrm{f}(\lambda)=\sum_{i=1}^{3}\left\{\mathrm{~A}_{1 \mathrm{i}} \mathrm{e}^{-\left(\frac{\lambda-\lambda_{0 i}}{\Delta \lambda_{1 i}}\right)^{2}}+\mathrm{A}_{2 \mathrm{i}} \mathrm{e}^{\left.-\left(\frac{\lambda-\lambda_{01}}{\Delta \lambda_{2 i}}\right)^{2}\right\}},\right.
$$

and a Lorentzian

$$
f(\lambda)=\sum_{i=1}^{3} \frac{A_{i} \Gamma_{i}}{\left(\lambda-\lambda_{0 i}\right)^{2}+\Gamma_{i}^{2}}
$$

Summations are over the three beam neutral species, A's are amplitudes, $\Delta \lambda$ 's are 1/e half-widths of the Gaussians, $\lambda_{0}$ 's are centroids, and $\Gamma$ 's are Lorentzian half-widths at half-maximum (HWHM). Free parameters are systematically varied until

$$
\chi^{2} \equiv \frac{1}{N-F-1} \sum_{i=1}^{N} \frac{\left(d_{i}-f_{i}\right)^{2}}{d_{i}}
$$

is a minimum. $d_{i}$ are the data values, $f_{i}$ are the fit values, $N$ is the number of data points, and $\mathrm{F}$ is the number of fitting parameters. Such a definition of $\chi^{2}$ equally weights the peaks and wings of the distribution. Fitting parameters are: centroid, width, and amplitude for each specie (full-, half-, and third-energy $\mathrm{D}^{0}$ ) for the Gaussian (9 total); centroid, width, amplitude, and $\alpha$ for each specie for the modified Gaussian (12); amplitude and width for each of the two Gaussians, located at a common centroid, for each specie for the sum of two Gaussians (15); centroid, width, and amplitude for each specie for the Lorentzian (9). 
Figure 3 presents the results of the fit for the simple Gaussian. (In this, and all succeeding fit result figures, the data and the fit to the data are plotted together. Plots are displayed as counts versus channel, for channels 1 through 300. Data points are shown as solid circles and fit points as plusses.) $\chi^{2}=250$. Both the peaks and the wings are badly underestimated. By replacing the $d_{i}$ weighting factors in the denominator of the definition of $\chi^{2}$ with unity, thereby weighting the peaks more heavily than the wings, it is found that the central portion of the peaks are well fit by a Gaussian. It is clear that a simple Gaussian cannot fit both the peak and the wings of the present spectrum.

Figure 4 gives the fit for the modified Gaussian distribution. $\chi^{2}$ is equal to 74 and the fit is considerably improved. However, the fit to the peaks is too sharp, and the fit in the wings, while improved, is still inadequate.

Results for the sum of two Gaussians are given in figure 5 , where $\chi^{2}=40$. This distribution was studied since it was known that the central portion of the peak is well fit by a Gaussian, and it was thought that a broad Gaussian might fit the wings. To a certain degree, such is the case. The fit to the wings is far superior to that in either of the two previous cases.

Finally, the results of the Lorentzian fit are shown in figure $6 . \chi^{2}$ for this case, 65 , is intermediate between that of the modified Gaussian and the sum of two Gaussians. As was the case of the sum of two Gaussians, the wings are fit reasonably well. Both the sum of two Gaussians and the Lorentzian provide acceptable fits to the entire spectrum.

While the fits obtained from the sum of two Gaussians and a Lorentzian are approximately equivalent, recall that the two Gaussian fit utilized fifteen fitting parameters versus nine for the Lorentzian. The latter fit is clearly the more physical of the two. Either function could be used to model beam transmission. 
However, due to the authors' familiarity with Gaussian functions, subsequent computations are made with the two Gaussian model.

The fits are summarized in Table I. Amplitudes, in counts, widths, in channels, and alphas (for the modified Gaussian) are given for each specie and for each distribution. Values for $\alpha$ are considerably different than one, producing a function more sharply peaked than a Gaussian and with substantial wings. Amplitudes for the Lorentzian are of a different order of magnitude than the Gaussian-based distributions because of the different normalization of equation 4 relative to equations 1-3.

From table I, ratios of the widths of the wide divergence to the narrow divergence for the two Gaussian distribution are 5.8 for the full-energy $\mathrm{D}^{0}$ specie, 3.5 for the half-energy $\mathrm{D}^{0}$, and 4 for the third-energy $\mathrm{D}^{0}$. A species weighted average of this ratio is 5.3. Ratios of the emission of the narrow part of the two Gaussian distribution to the combined emission are 0.66 for the full-energy $\mathrm{D}^{0}$, 0.41 for the half-energy $D^{0}$, and 0.58 for the third-energy $D^{0}$. A species weighted average of 0.6 is found for this ratio. Beam transmission and power density will subsequently be studied assuming $60 \%$ of the power is in the narrow part of the distribution and the broad part has a divergence 5.3 times that of the narrow part.

\section{BEAM TRANSMISSION}

Beam transmission to the calorimeter will be computed and compared for several of the distributions under consideration. It is computed only in the direction perpendicular to the grid rails, the direction in which the Dopplershifted line emission has been measured; it is computed as the fraction of the extracted power delivered through the $60 \mathrm{~cm}$ tall calorimeter entrance collimator 
located $510 \mathrm{~cm}$ downstream of the ion source. A closed analytical expression can be developed for all but the modified Gaussian. For a Gaussian, the transmission is $^{18}$

$$
\frac{y_{0}^{\prime} L}{2 y_{0}}\left\{\frac{y+y_{0}}{y_{0}^{\prime} L} \operatorname{erf}\left(\frac{y+y_{0}}{y_{0}^{\prime} L}\right)-\frac{y-y_{0}}{y_{0}^{\prime} L} \operatorname{erf}\left(\frac{y-y_{0}}{y_{0}^{\prime} L}\right)+\frac{1}{\sqrt{\pi}}\left[e^{-\left(\frac{y+y_{0}}{y_{0}^{\prime} L}\right)^{2}}-e^{-\left(\frac{y-y_{0}}{y_{0}^{\prime} L}\right)^{2}}\right]\right\},
$$

whereas for a Lorentzian it is

$\frac{y_{0}^{\prime} L}{\pi y_{0}}\left\{\frac{y+y_{0}}{y_{0}^{\prime} L} \tan ^{-1}\left(\frac{y+y_{0}}{y_{0}^{\prime} L}\right)-\frac{y-y_{0}}{y_{0}^{\prime} L} \tan ^{-1}\left(\frac{y-y_{0}}{y_{0}^{\prime} L}\right)+\frac{1}{2} \ln \left[1+\left(\frac{y-y_{0}}{y_{0}^{\prime} L}\right)^{2}\right]-\frac{1}{2} \ln \left[1+\left(\frac{y+y_{0}}{y_{0}^{\prime} L}\right)^{2}\right]\right\}$

In both cases, $\mathrm{y}$ is the half-height of the collimator, $\mathrm{L}$ is the distance from the ion source to the collimator, $y_{0}$ is the half-height of the ion source, and $y_{0}^{\prime}$ is the $1 / e$ divergence.

Beam divergence will be computed from the line widths in Table I. For a photon emitted from an atom with velocity v viewed at angle $\theta$, the Doppler shift is

$$
\Delta \lambda=\lambda_{0} \frac{\mathrm{v}}{\mathrm{c}} \cos \left(\theta+\theta_{\mathrm{e}}\right)
$$

where $\lambda_{0}$ is the wavelength of the unshifted line, $c$ is the speed of light, and $\theta_{\mathrm{e}}$ is the divergence. There are two parts to the shift. First, due to the viewing angle $\theta$ $\left(60^{\circ}\right.$ in our case), is the shift of the centroid of the Doppler-shifted line from the unshifted line. The second part, due to the divergence $\theta_{e}$, is the shift of the $1 / \mathrm{e}-$ point on a Gaussian distribution from the shifted line's centroid. From equation 
8 , the sum of these two shifts is

$$
\Delta \lambda=\Delta \lambda_{0}+\Delta \lambda_{\mathrm{e}}=\lambda_{0} \frac{\mathrm{v}}{\mathrm{c}}\left(\cos \theta-\theta_{\mathrm{e}} \sin \theta\right) .
$$

From this, the divergence is computed in terms of the $1 / \mathrm{e}$ line widths, $\Delta \lambda_{\mathrm{e}}$ :

$$
\theta_{e}=\frac{c \Delta \lambda_{e}}{v \lambda_{0} \sin 60^{\circ}}
$$

Total beam divergence is computed as a weighted sum of the divergences for each specie. Individual divergences for the narrow parts of the two Gaussian case are $1^{\circ}, 0.8^{\circ}$, and $1.1^{\circ}$ for the full-, half-, and third-energy $\mathrm{D}^{0}$, respectively. Error bars on these values are approximately $10 \%$, due to the fitting process. The species weighted average divergence is $1^{\circ} \pm 0.1^{\circ}$. This value compares favorably with that of $1.3^{\circ}$ obtained from deconvolution of the calorimeter thermal profile for operation under the same conditions. Similarly, for the wide part of the distribution, the species weighted average divergence is $5.3^{\circ}$. For the Lorentzian distribution, equations 8-10 can be used, but with $\theta_{\mathrm{e}}$ changed to $\Gamma$. Values of $\Gamma$ from the results in Table I are $0.7^{\circ}, 0.85^{\circ}$, and $0.7^{\circ}$ for the full-, half-, and thirdenergy $D^{0}$, respectively. The species weighted Lorentzian HWHM divergence is $0.73^{\circ}$.

For a Gaussian with a nominal 1/e half-width divergence of $1^{\circ}$, the transmission of the beam from the ion source to the calorimeter is $~ 98 \%$. Only $2 \%$ of the beam is lost. For the sum of two Gaussians, $60 \%$ of the beam has a divergence of $1^{\circ}$ and $40 \%$ has $5.3^{\circ}$. Transmission of the wide part of the distribution to the calorimeter is $60 \pm 4 \%$. The total loss is therefore $17 \pm 2 \%$. For a 
Lorentzian with a HWHM divergence of $0.73^{\circ}$ the transmission to the calorimeter is also $83 \%$. The loss of $17 \%$ is, however, somewhat less than the measured loss of $20-30 \%$. Error bars of $\pm 5 \%$ in the waterflow calorimetry measurement translate into an error bar of $\pm 4 \%$ on the loss in this case. While the prediction is within the error bars, it is believed that there are other loses not yet accounted for. These could be due to nonuniform extraction of the molecular ions, ${ }^{31}$ or to wings on the beam distribution in the direction parallel to the grid rails.

Both the sum of two Gaussians and the Lorentzian distributions provide least square fits which are good representations of the Doppler-shifted line shape. Predicted beam losses are dominated by the wings of the distribution functions with $40 \%$ of the wide part of the two Gaussian distribution lost in the first $5 \mathrm{~m}$ of transport.

\section{POWER DENSITY}

One-dimensional power density profiles will be computed for two emitter distributions: a Gaussian and the sum of two Gaussians. Power density is computed in the vertical direction, i. e., perpendicular to the grid rails. It is given by a convolution of the emitted distribution function over the extraction area (a line in this case). For a simple Gaussian one finds ${ }^{18}$

$$
p(y, L)=\frac{1}{4 y_{0}}\left[\operatorname{erf}\left(\frac{y+y_{0}}{y_{0}^{\prime} L}\right)+\operatorname{erf}\left(\frac{y-y_{0}}{y_{0}^{\prime} L}\right)\right]
$$


where $L, y_{0}$, and $y_{0}^{\prime}$ have been defined above and $y$ is the distance of the point in question from the beam axis. Total power density is the product of three terms: $p(y, L), p(x, L)$, and the total power. Interest here lies in the shape of the profile in the y-direction. Locations chosen for the calculation are $10 \mathrm{~cm}$ from the source, the end of the neutralizer $(\mathrm{L}=290 \mathrm{~cm})$, and in the duct connecting the beamline to the torus $(\mathrm{L}=919 \mathrm{~cm})$.

Power density is computed using equation 11 for the simple Gaussian, and the weighted sum of two such terms for the sum of two Gaussians. In the latter case, $60 \%$ of the extracted power has a divergence of $1^{\circ}$ and $40 \%$ has a divergence of $5.3^{\circ}$. Results of the calculations are given in figures 7-9, for the locations of $10 \mathrm{~cm}$ from the source, the end of the neutralizer, and the duct, respectively. Each plot is normalized to unity at the maximum value of the peak power density at that location. Normalized power density is plotted versus distance above the beam axis. Since the beam is symmetric with respect to the beam axis, only half of the profile is plotted. Vertical lines in figures 8 and 9 correspond to the height of the collimator. That portion of the beam extending beyond the collimator is scraped.

Close to the ion source, figure 7, power densities for the two cases are similar. The convolution produces a shape that is flat in the center and Gaussian-like at the edge. The edge of the beam in the simple Gaussian case is much sharper than that for the sum of two Gaussians because of the latter's wings. By the time the beam reaches the end of the neutralizer, figure 8 , the $1 / \mathrm{e}$ width of the $1^{\circ}$ Gaussian is $5.1 \mathrm{~cm}$, a value only $25 \%$ of the half-height of the source. As a result, the shape is still somewhat flat at the top, but the two Gaussian case exhibits a pronounced tail. A significant fraction of the beam is scraped at this location: $2 \%$ of the narrow portion of the distribution and $28 \%$ of the fat part, giving a weighted loss of $12 \%$; a value in good agreement with waterflow calorimetry measurements 
in the neutralizer. In the duct, figure 9 , the beam shape in both cases resembles that of the emitting distribution.

Ratios of the peak power densities for the two distributions are not strongly dependent on $L$. The ratio approaches 0.6 , the narrow divergence fraction of the total power, at large distances from the ion source. Differences between the cases in the wings of the power density distribution, by comparison, are quite pronounced. At the end of the neutralizer, the scrapeoff loss is fourteen times greater for the two Gaussian distribution than for the simple Gaussian. The wings of the broad part of the distribution are severely scraped before the beam has travelled many meters from the ion source. As a result, an OMA, or other beam profile diagnostic, cannot determine the wings of the extracted beam if it is located more than a few meters from the ion source.

Several other interesting effects are also noted. First, since the peak power densities of the two Gaussian distribution are less than that of the single Gaussian with the same power, components that absorb the entire beam will be subjected to lower power densities than thrught. These components include the calorimeter and the ion dump. At the location of these items, the reduction in peak power density is $\sim 25 \%$. Finally, the model predicts a loss of approximately $4 \%$ of the beam in the drift duct. While not a concern for present pulse lengths on TFTR, it must be accommodated on TPX.

\section{ANGLE OF INCIDENCE}

Power densities computed above are for normal beam incidence. In practice, beam absorbing surfaces are inclined to the beam to increase the heated area, 
and, thereby, decrease the surface power density. For example, the TFTR calorimeter is inclined at an angle of $6^{\circ}$ relative to the beam and the ion dump intercepts the beam at an angle of $30^{\circ}$. A correction must be applied to the normal incidence power densities to accommodate the angle of incidence.

As an example of this correction, beam deposition at the end of the neutralizer will be examined. The neutralizer is $50 \mathrm{~cm}$ tall and its end is $290 \mathrm{~cm}$ downstream of the ion source accelerator, which is $43.7 \mathrm{~cm}$ tall. While the beam axis is parallel to the neutralizer walls, the included angle between a line from the center of the ion source to the end of the neutralizer and the neutralizer wall is $4.95^{\circ}$. This value is a good intuitive guess to the angle of incidence, however, a better estimate can be made. Since the emitting surface is an extended source, i.e., it is $43.7 \mathrm{~cm}$ tall, the angle at which an emitted particle strikes the neutralizer is a function of its point of origin. The range of possible angles is bounded by the angles subtended by lines from by the top and bottom of the accelerator to the exit aperture of the neutralizer and the neutralizer wall, i.e., $0.65^{\circ}$ and $9.19^{\circ}$.

The average angle of incidence of those particles striking the downstream edge of the neutralizer is:

$$
\bar{\theta}=\frac{\int_{y_{0}}^{y_{0}}\left(\frac{y_{1}-y}{L}\right) \exp \left[-\left(\frac{y_{1}-y}{y_{0}^{\prime} L}\right)^{2}\right] d y}{\int_{-y_{0}}^{y_{0}} \exp \left[-\left(\frac{y_{1}-y}{y_{0}^{\prime} L}\right)^{2}\right] d y}
$$

where $L, y_{0}$, and $y_{0}^{\prime}$ have been defined above and $y_{1}$ is the half-height of the neutralizer. The first term in the numerator is the intercept angle at the end 
neutralizer and the second part is the weighting factor, i.e., the distribution function. Carrying out the integral yields the average angle of incidence:

$$
\bar{\theta}=\frac{\frac{y_{0}^{\prime}}{\sqrt{\pi}}\left\{\exp \left[-\left(\frac{y_{1}-y_{0}}{y_{0}^{\prime} L}\right)^{2}\right]-\exp \left[-\left(\frac{y_{1}+y_{0}}{y_{0}^{\prime} L}\right)^{2}\right]\right\}}{\operatorname{erf}\left(\frac{y_{1}+y_{0}}{y_{0}^{\prime} L}\right)-\operatorname{erf}\left(\frac{y_{1}-y_{0}}{y_{0}^{\prime} L}\right)}
$$

This expression is plotted as a function of divergence, $y_{0}^{\prime}$, in figure 10 for the Gaussian distribution. For a divergence of $1^{\circ}$, the figure indicates an angle of $1.04^{\circ}$, a value significantly less than that subtended by the center of the source. The resulting power density is fives times less than that of assuming an angle of incidence subtended by the center of the ion source. For the case of the sum of two Gaussians, the average angle of incidence is obtained by appropriately weighting the contributions from the two Gaussian components. The result is an angle of $1.9^{\circ}$, a value approximately twice that of the simple Gaussian.

As divergence increases, the average angle of incidence asymptotically approaches $4.95^{\circ}$ due to the fact that all points on the source can reach the end of the neutralizer with equal likelihood. In the limit of zero divergence the average angle of incidence approaches $0.65^{\circ}$, the angle subtended by the top of the source. For small divergence, only particles emitted from the closest part of the source can reach the aperture.

In cases of grazing incidence on apertures close to the ion source, the correction to the power density for the angle of incidence can differ by a large factor from an intuitive guess. It is this fact which keeps the TFTR neutralizer from being destroyed in the presence of high beam loss. 


\section{ACKNOWLEDGEMENTS}

The authors would like to thank all of the TFTR neutral beam technicians, mechanical, electrical, and ion source, who are little noticed, but without whom no experiments could be performed. One of the authors, JHK, would also like to acknowledge many fruitful conversations with Klaus Halbach dealing with the calculation of beam power density. This work was supported by the United States Department of Energy under contract No. DE-AC02-CHO-3073. 


\section{REFERENCES}

${ }^{\dagger}$ Present address: TIMET, Henderson, AZ.

${ }^{1}$ T. Stevenson, J. Kamperschroer, L. Dudek, L. Grisham, R. Newman, T. O'Connor, A. von Halle, and M. D. Williams, Proceedings of the Fourteenth Symposium on Fusion Engineering, San Diego, 1991 (IEEE, New York, 1992), Vol. 2, p. 908.

2J. Kim, R. W. Callis, A. P. Colleraine, J. Cummings, A. S. Glad, A. M. Gootgeld, J. S. Haskovec, R. Hong, D. H. Kellman, A. R. Langhorn, R. L. Lee, A. Nerem, J. C. Phillips, K. Schaubel, R. Senior, B. W. Sleaford, J. F. Tooker, M. L. Tupper, and J. J. Wight, Proceedings of the Twelfth Symposium on Fusion Engineering, Monterey, 1987 (IEEE, New York, 1987), Vol. 1, p. 290.

${ }^{3}$ R. Hong, A. P. Colleraine, D. H. Kellman, J. Kim, J. L. Luxon, A. Nerem, J. Phillips, and J. Wight, Proceedings of the Seventeenth Symposium on Fusion Technology, Rome, 1992 (Elsevier, Amsterdam, 1993), Vol. 1, p. 529.

${ }^{4}$ A. Stäbler, J. -H. Fiest, E. Sreth, J. L. Dunne, S. Goetz, B. Heinemann, A. Krauss, R. -C. Kunze, H. Lohnert, J. Sielanko, W. Szyszko, O. Vollmer, and K. Wittenbecher, Proceedings of the Fifteenth Symposium on Fusion Technology, Utrecht, 1988 (Elsevier, Amsterdam, 1989), Vol. 1, p. 620.

${ }^{5}$ H. Euringer, M. Lochter, U. Pfister, and R. Uhlemann, Proceedings of the Thirteenth Symposium on Fusion Engineering, Knoxville, 1989 (IEEE, New York, 1990), Vol. 2, p. 991.

${ }^{6}$ H. Horiike, M. Akiba, M. Araki, M. Dairaku, T. Itoh, M. Kawai, M. Kuriyama, S. Kitamura, S. Matsuda, M. Matsuoka, K. Mizuhasłi, Y. Oguchi, Y. Ohara, T. Ohga, Y. Okumura, K. Shibanuma, T. Shibata, H. Shigematsu, H. Shirakata, T. Sugawara, S. Tanaka, and K. Watanabe, Rev. Sci. Instrum. 55, 332 (1984). 
${ }^{7}$ D. Stork, Proceedings of the Sixteenth Symposium on Fusion Technology, London, 1990 (Elsevier, Amsterdam, 1991), Vol. 1, p. 111.

${ }^{8}$ M. Fumelli, P. Bayetti, R. Becherer, F. Bottiglioni, M. Desmons, F. Jequier, J. Pamela, P. Raimbault, and F. P. G. Valckx, Rev. Sci. Instrum. 57, 1266 (1986).

${ }^{9}$ M. M. Menon, C. C. Tsai, J. H. Whealton, D. E. Schechter, G. C. Barber, S. K. Combs, W. K. Dagenhart, W. L. Gardner, H. H. Haselton, N. S. Ponte, P. M. Ryan, W. L. Stirling, and R. E. Wright, Rev. Sci. Instrum. 56, 242 (1985).

${ }^{10}$ M. C. Vella, P. A. Pincosy, C. A. Hauck, and R. V. Pyle, Lawrence Berkeley Laboratory Report No. LBL-17550, August 1984.

11P. Bayetti, R. Becherer, F. Bottiglioni, C. Jacquot, F. Jequier, M. Fumelli, P. Lotte, J. Pamela, Z. Sledziewski, Proceedings of the Fifteenth Symposium on Fusion Technology, Utrecht, 1988 (Elsevier, Amsterdam, 1989), Vol. 1, p. 604.

${ }^{12}$ T. Mutoh, Y. Takeiri, T. Obiki, F. Sano, A. Fukuyama, K. Hanatani, S. Kubo, O. Kaneko, R. Kumazawa, Y. Nakamura, K. Narihara, H. Okada, M. Sato, T. Shoji, M. Hosokawa, E. Kako, T. Aoki, T. Watari, M. Ohnishi, T. Kuroda, S. Kitagawa, K. Yamazaki, O. Motojima, N. Ohyabu, M. Fujiwara, A. Iiyoshi, Proceedings of the Fifteenth Symposium on Fusion Technology, Utrecht, 1988 (Elsevier, Amsterdam, 1989), Vol. 1, p. 552.

${ }^{13}$ P. Purgalis, O. A. Anderson, W. S. Cooper, G. E. DeVries, A. F. Lietzke, W. B. Kunkel, J. W.Kwan, C. A. Matuk, T. Nakai, J. W. Stearns, L. Soroka, R. P. Wells, W. B. Lindquist, W. S. Neef, L. L. Reginato, D. W. Sedgley, J. W. Brook, T. E. Luzzi, and T. J. Meyers, Proceedings of the Thirteenth Symposium on Fusion Engineering, Knoxville, 1989 (IEEE, New York, 1990), Vol. 2, p. 1444.

${ }^{14}$ B. D. Murphy, J. H. Whealton, G. E. McMichael, W. R. Becraft, and H. H. Haselton, Nucl. Instrum. \& Meth. A275, 157 (1989). 
15P. D. Weber, H. M. Owren, J. A. Paterson, P. A. Pincosy, R. V. Pyle, R. P. Wells, and M. C. Vella, Rev. Sci. Instrum. 57, 2714 (1986).

16 J. J. Wight, A. P. Colleraine, R. Hong, J. Kim, J. C. Phillips, and B. W. Sleaford, Proceedings of the Twelfth Symposium on Fusion Engineering, Monterey, 1987 (IEEE, New York, 1987), Vol. 2, p. 1126.

17J. H. Kamperschroer, L. R. Grisham, L. E. Dudek, G. M. Gammel, G. A. Johnson, H.W. Kugel, L. Lagin, T. E. O'Connor, P. A. Shah, P. Sichta, T. N. Stevenson, A. von Halle, and M. D. Williams, Rev. Sci. Instrum. 60, 3377 (1989).

${ }^{18} \mathrm{~J}$. Kim and J. H. Whealton, Nucl. Instrum. Meth. 141, 187 (1977).

${ }^{19}$ C. F. Burrell, W. S. Cooper, W. F. Steele, and R. R. Smith, Proceedings of the Seventh Symposium on Engineering Problems of Fusion Research, Knoxville, 1977 (IEEE, New York, 1977), Vol. 1, p. 374.

${ }^{20}$ W. Ott and F.-P. Penningsfeld, Max-Planck Institute for Plasma Physics Report No. IPP 4/258, January 1993.

21J. Kim and L. D. Stewart, Fusion Technology 8, 1717 (1985).

${ }^{22}$ L. C. Pittenger, R. R. Stone, L. E. Valby, and L. R. Pedrotti, Proceedings of the Seventh Symposium on Engineering Problems of Fusion Research, Knoxville, 1977 (IEEE, New York, 1977), Vol. 1, p. 555.

${ }^{23}$ K. Lou, D. Roth, J. Haughian, R. Nemetz, G. Newell, R. Byrns, and A. Roberts, Proceedings of the Eighth Symposium on Engineering Problems of Fusion Research, San Francisco, 1979 (IEEE, New York, 1979), Vol. 2, p. 967.

${ }^{24}$ M. C. Vella, W. S. Cooper, P. A. Pincosy, R. V. Pyle, P. D. Weber, and R. P. Wells, Rev. Sci. Instrum. 59, 2357 (1988).

${ }^{25}$ C. F. Burrell, W. S. Cooper, R. R. Smith, and W. F. Steele, Rev. Sci. Instrum. 51, 1451 (1980). 
${ }^{26}$ J. H. Kamperschroer, H. W. Kugel, M. A. Reale, S. L. Hayes, G. A. Johnson, J. L. Lowrance, P. A. Shah, P. Sichta, B. W. Sleaford, M. D. Williams, and P. M. Zucchino, Rev. Sci. Instrum. 58, 1362 (1987).

${ }^{27}$ J. F. Bonnal, G. Bracco, C. Breton, C. de Michelis, J. Druaux, M. Mattioli, R. Oberson, and J. Ramette, J. Phys. D 15, 805 (1982).

${ }^{28}$ G. A. Cottrell, A. R. Martin, and C. Padgett, Proceedings of the Second Joint Grenoble-Varenna International Symposium on Heating in Toroidal Plasmas, Como, Italy, 1980 (Euratom, Brussels, 1981), Vol. 2, p. 945.

${ }^{29}$ G. H. Deschamps, H. D. Falter, R. S. Hemsworth, and P. Massmann, Proceedings of the Fifteenth Symposium on Fusion Technology, Utrecht, 1988 (Elsevier, Amsterdam, 1989), Vol. 1, p. 588.

${ }^{30}$ J. H. Kamperschroer, L. R. Grisham, R. A. Newman, T. E. O'Connor, T. N. Stevenson, A. von Halle, M. D. Williams, and K. E. Wright, Rev. Sci. Instrum. 64, 2729 (1993).

${ }^{31}$ J. H. Kamperschroer, L. R. Grisham, H. W. Kugel, T. E. O'Connor, T. N. Stevenson, A. von Halle, and M. D. Williams, Rev. Sci. Instrum. 63, 3701 (1992). 
Table I. Fit Parameters for each of the three beam species for all four models

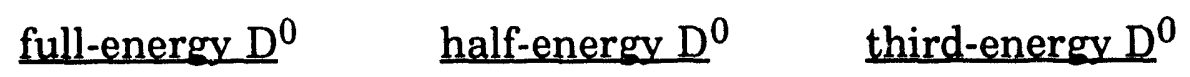

Gaussian

amplitude (counts) 9800

width (channel) $\quad 11.8$

4300

4200

13.9

9.5

Gaussian $^{\alpha}$

amplitude

16800

8200

7200

width

5.6

6.45

4.8

alpha

0.35

0.43

0.40

two Gaussians

amplitude

10400

4900

4600

width

9.1

5.1

5.7

amplitude \#2

900

1990

840

width \#2

53

18

23

Lorentzian

amplitude

80000

38000

24000

width

6.3

5.4

3.9 


\section{FIGURE CAPTIONS}

Figure 1. Schematic elevation view of a TFTR neutral beamline. The ion source and OMA diagnostic are located on the right side.

Figure 2. OMA spectrum of a typical beam pulse. Data points are plotted as counts per channel versus channel (wavelength). At the right is the large unshifted $D \alpha$ line of the neutralizer gas. To its left are the three principal Doppler-shifted lines.

Figure 3. Comparison of the data from the three Doppler-shifted peaks with a Gaussian fit to the data.

Figure 4. Comparison of the data from the three Doppler-shifted peaks with a modified Gaussian fit to the data.

Figure 5. Comparison of the data from the three Doppler-shifted peaks with a sum of two Gaussians fit to the data.

Figure 6. Comparison of the data from the three Doppler-shifted peaks with a Lorentzian fit to the data.

Figure 7. Normalized power density in the vertical direction, as a function of height above the beam axis. Calculated at a location $10 \mathrm{~cm}$ downstream of the ion source for a Gaussian distribution and the sum of two Gaussians. 
Figure 8. Normalized power density in the vertical direction, as a function of height above the beam axis. Calculated at the end of the neutralizer, $290 \mathrm{~cm}$ downstream of the ion source, for a Gaussian distribution and the sum of two Gaussians.

Figure 9. Normalized power density in the vertical direction, as a function of height above the beani axis. Calculated in the drift duct, $919 \mathrm{~cm}$ downstream of the ion source, for a Gaussian distribution and the sum of two Gaussians.

Figure 10. Average angle of incidence for beam power lost at the exit of the neutralizer as a function of beam divergence. Computed for a simple Gaussian distribution. 


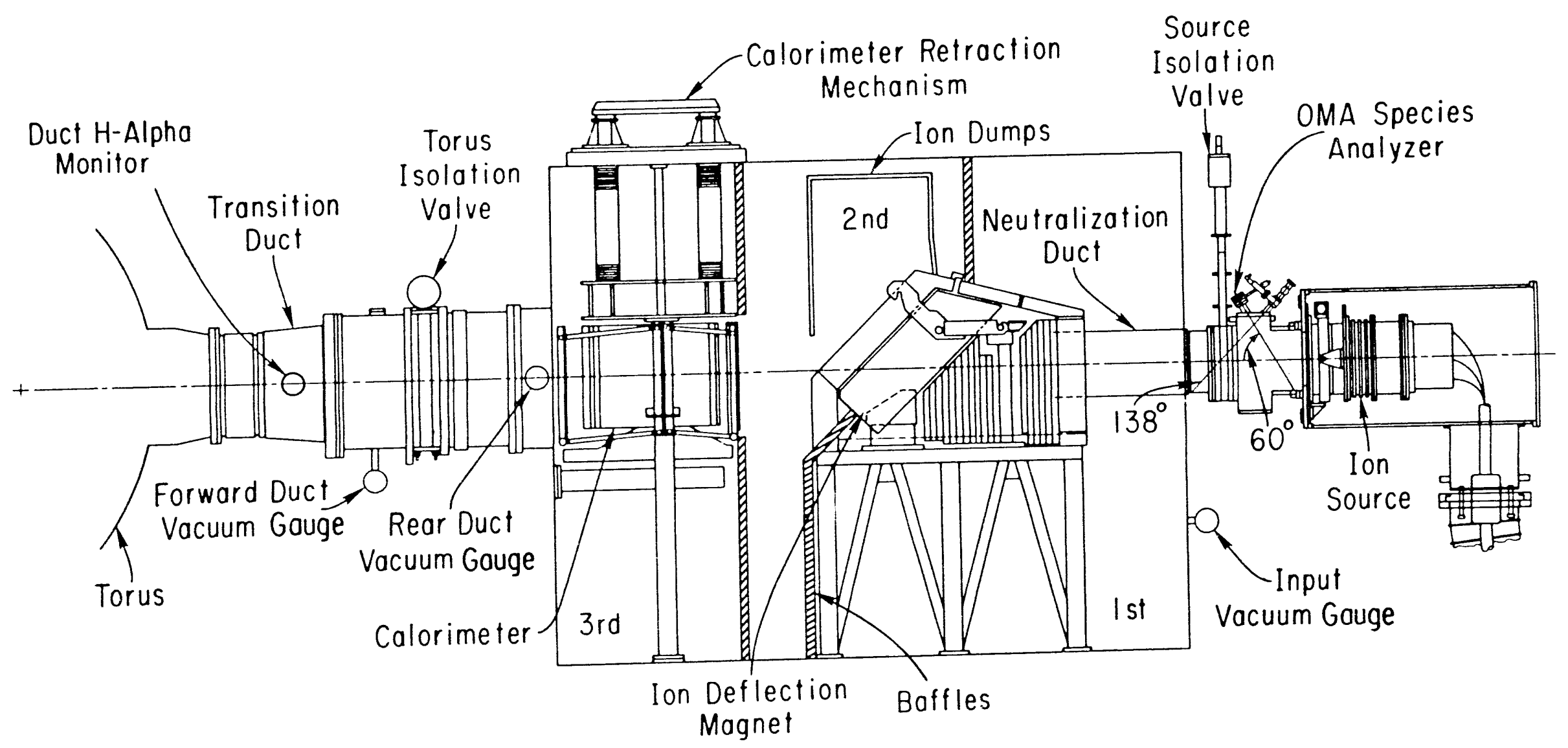




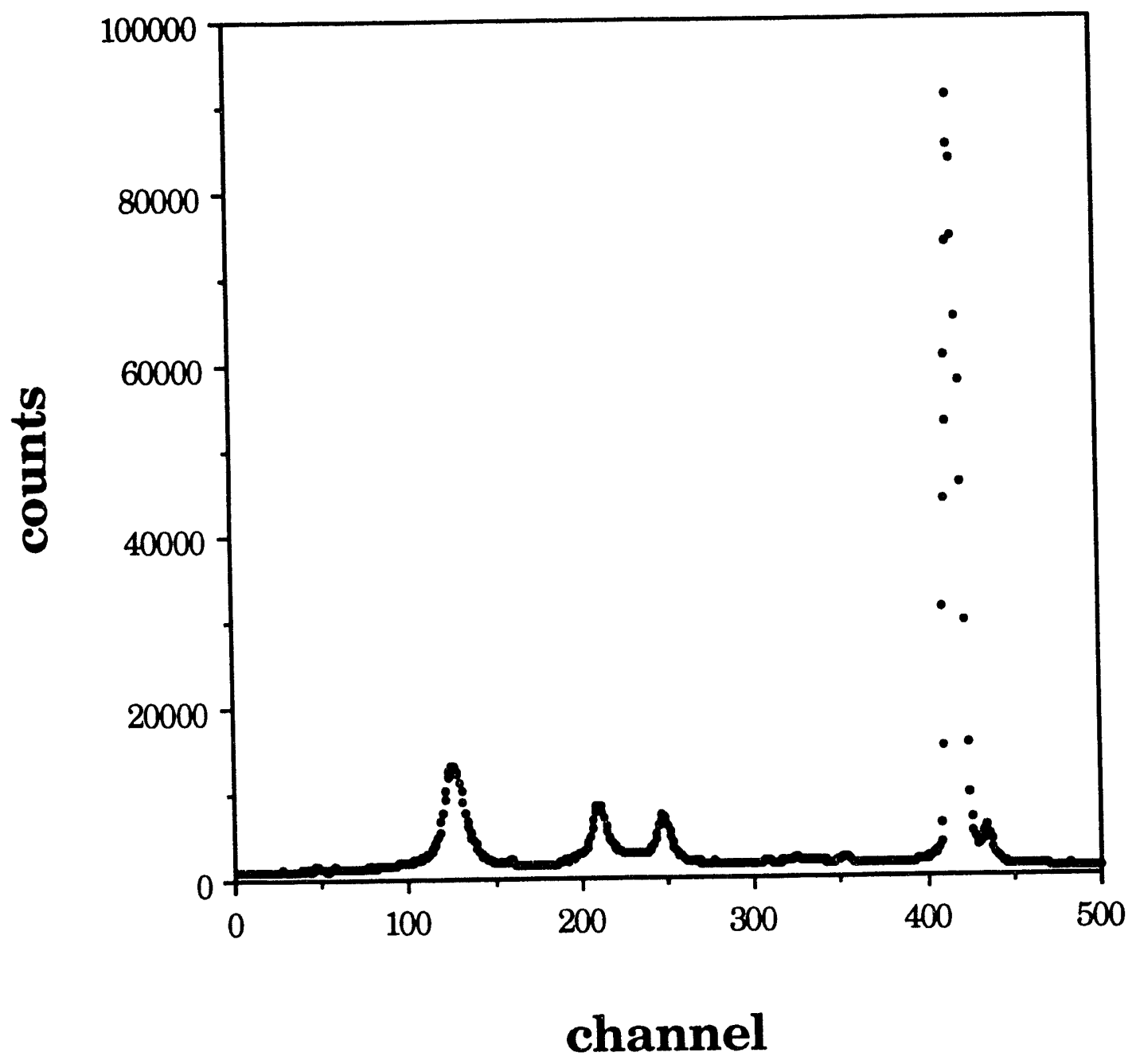

Fig. 2 


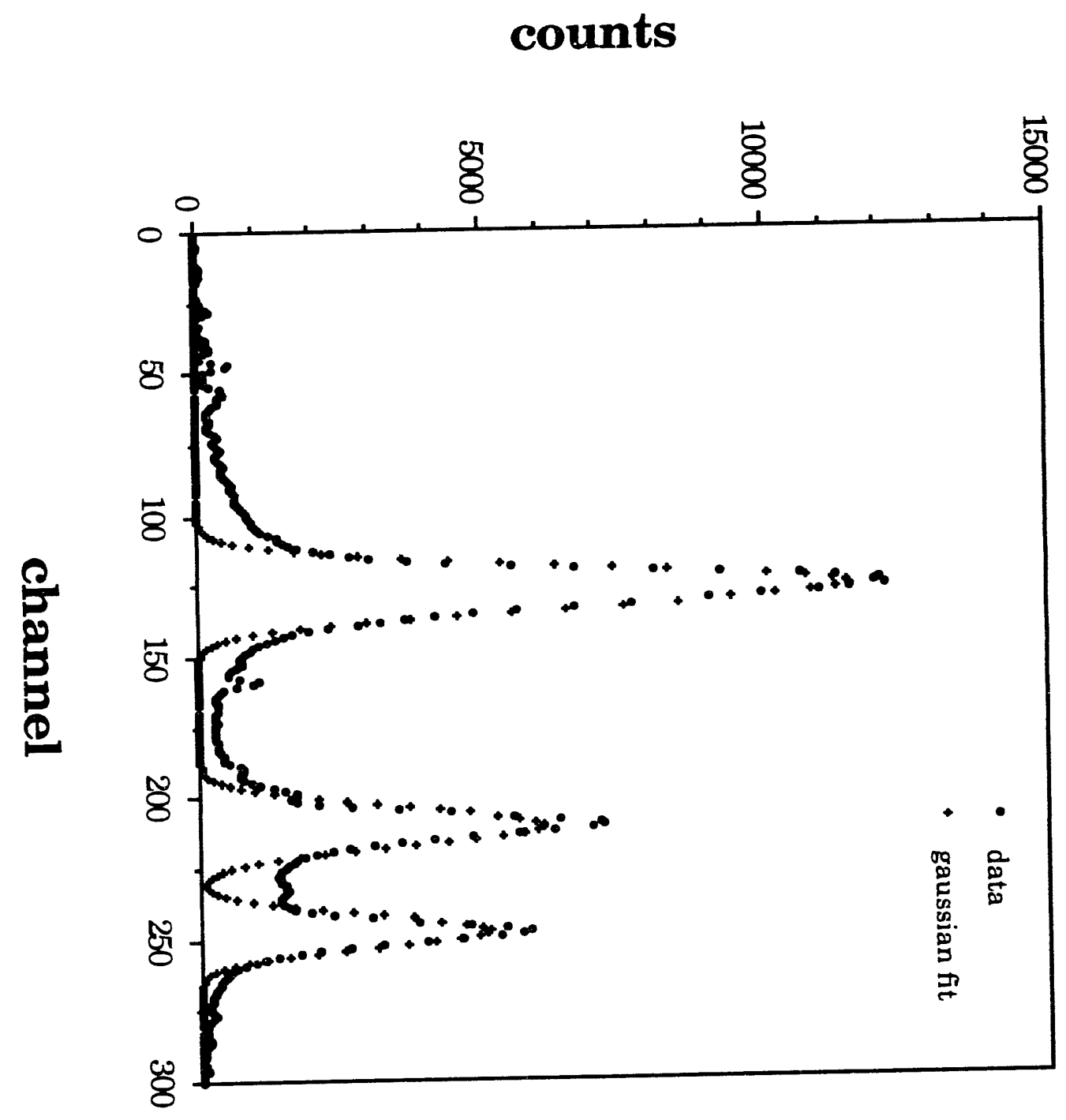




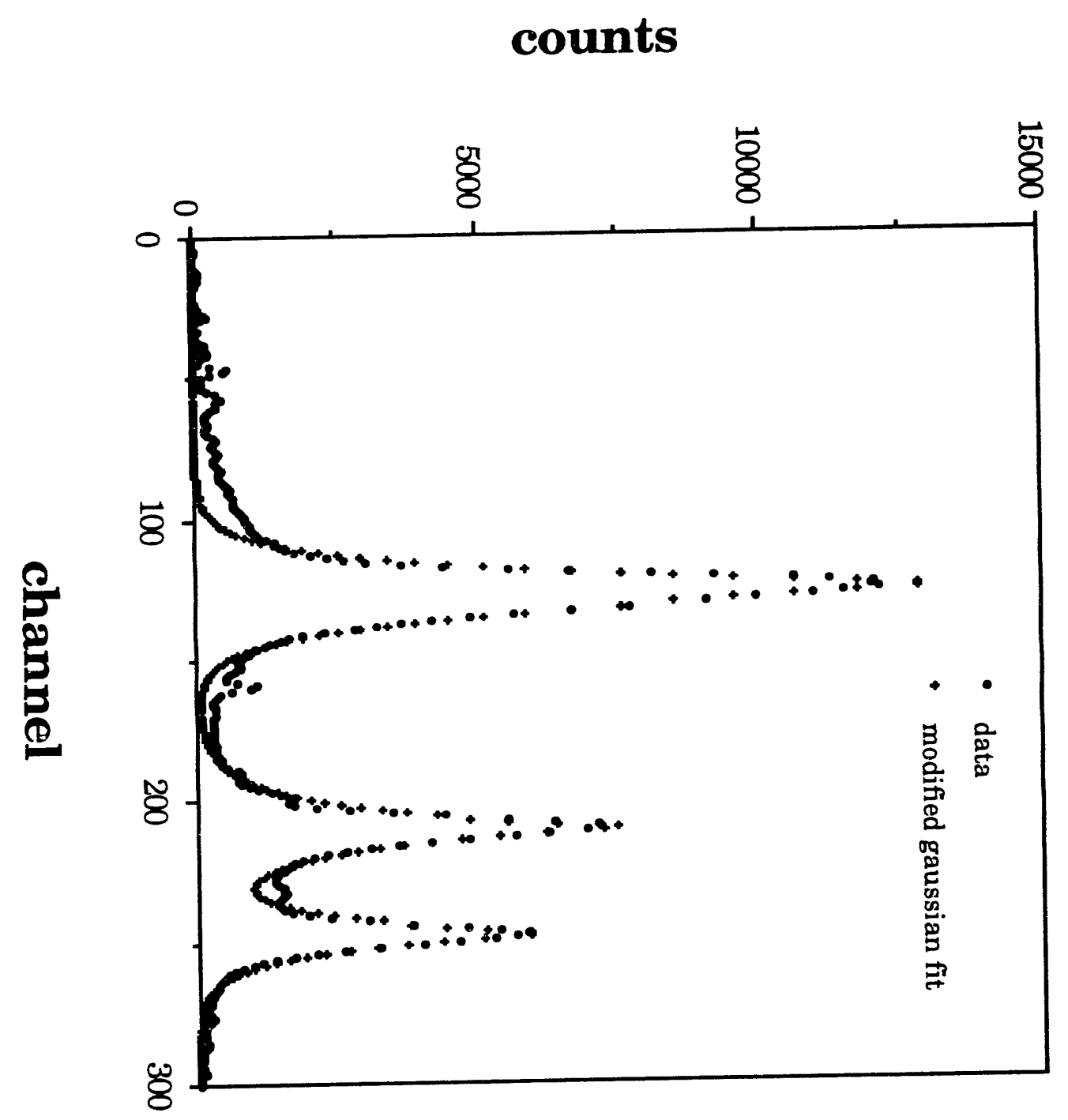




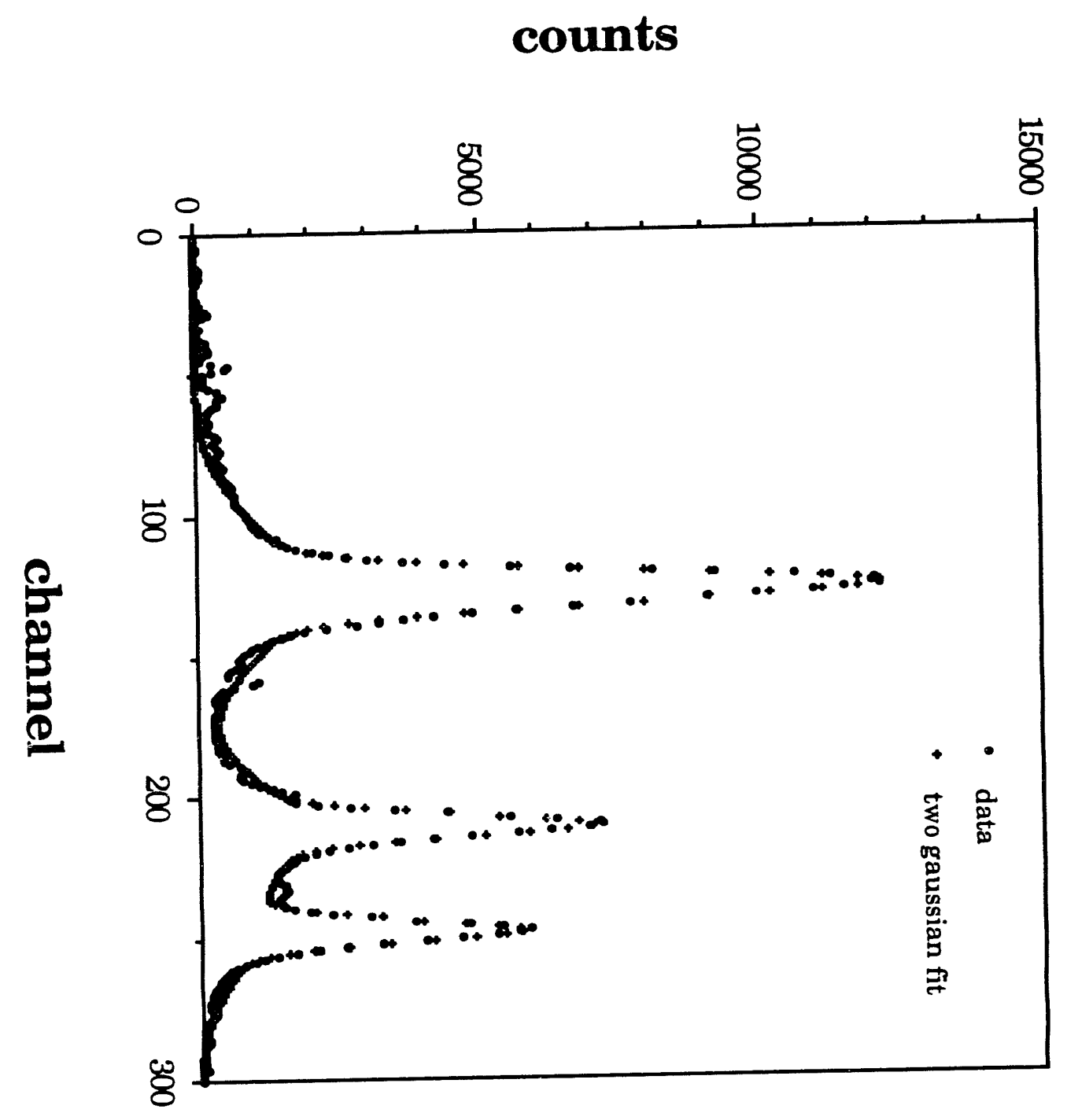




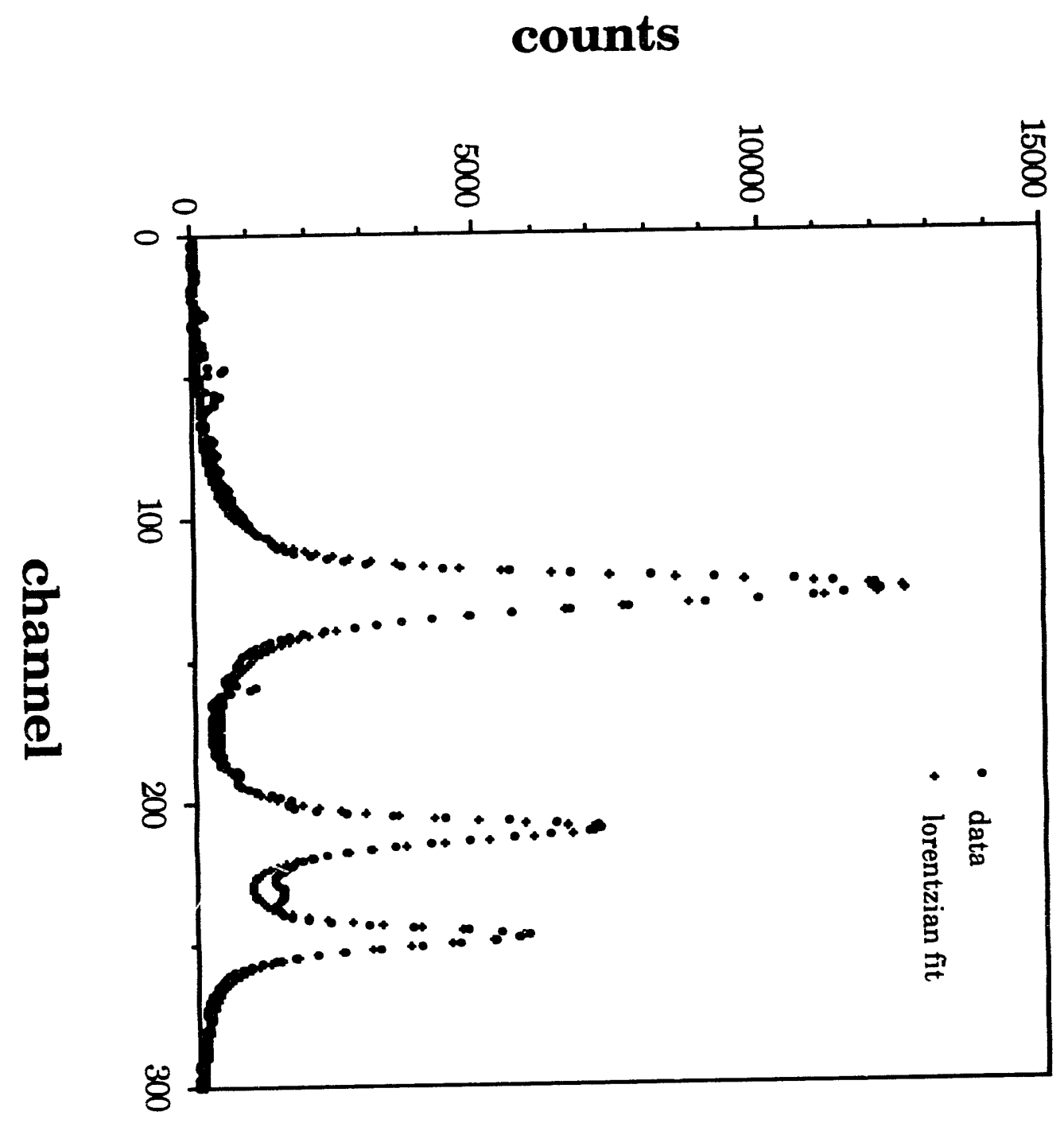




\section{normalized power density}

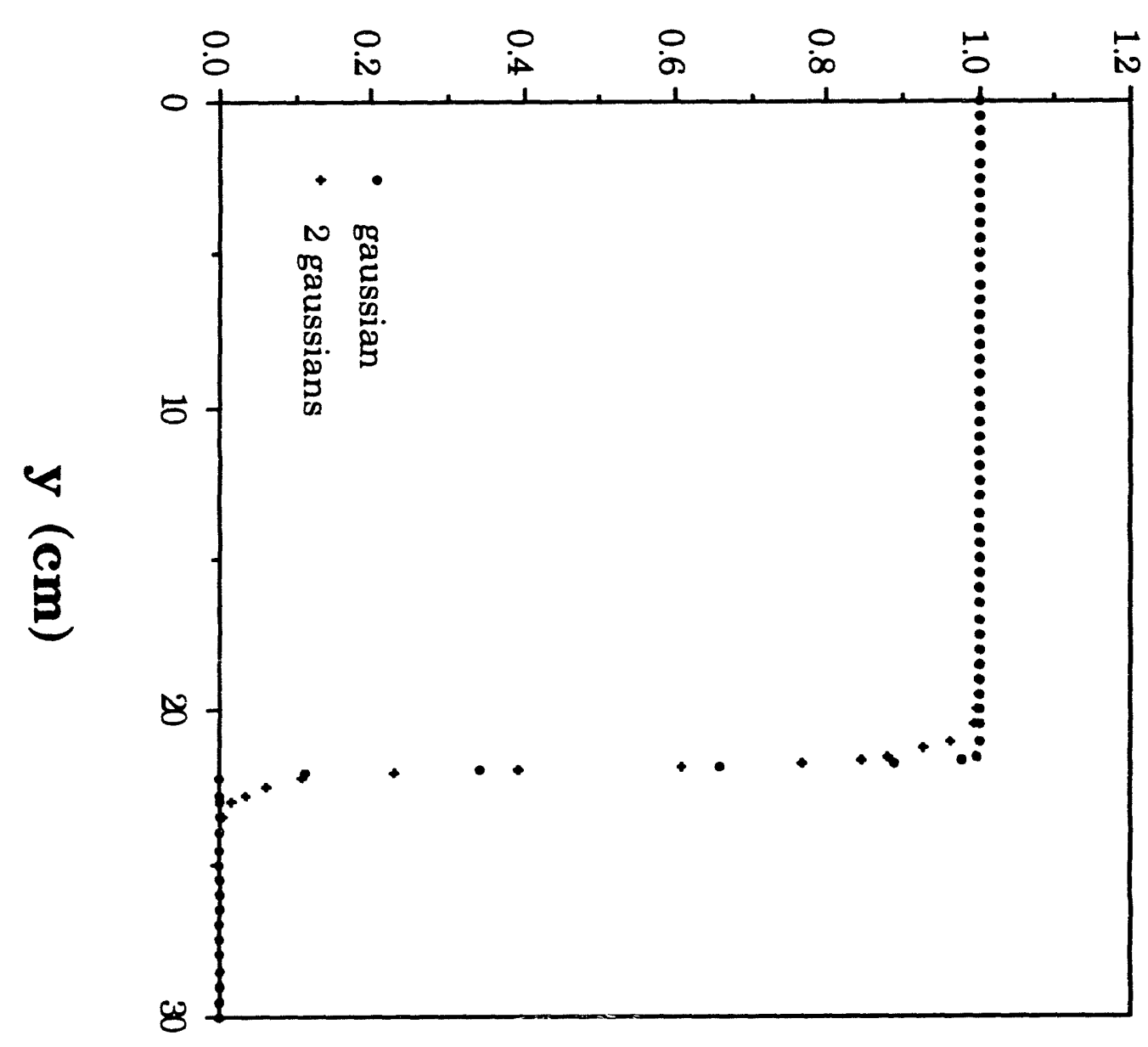




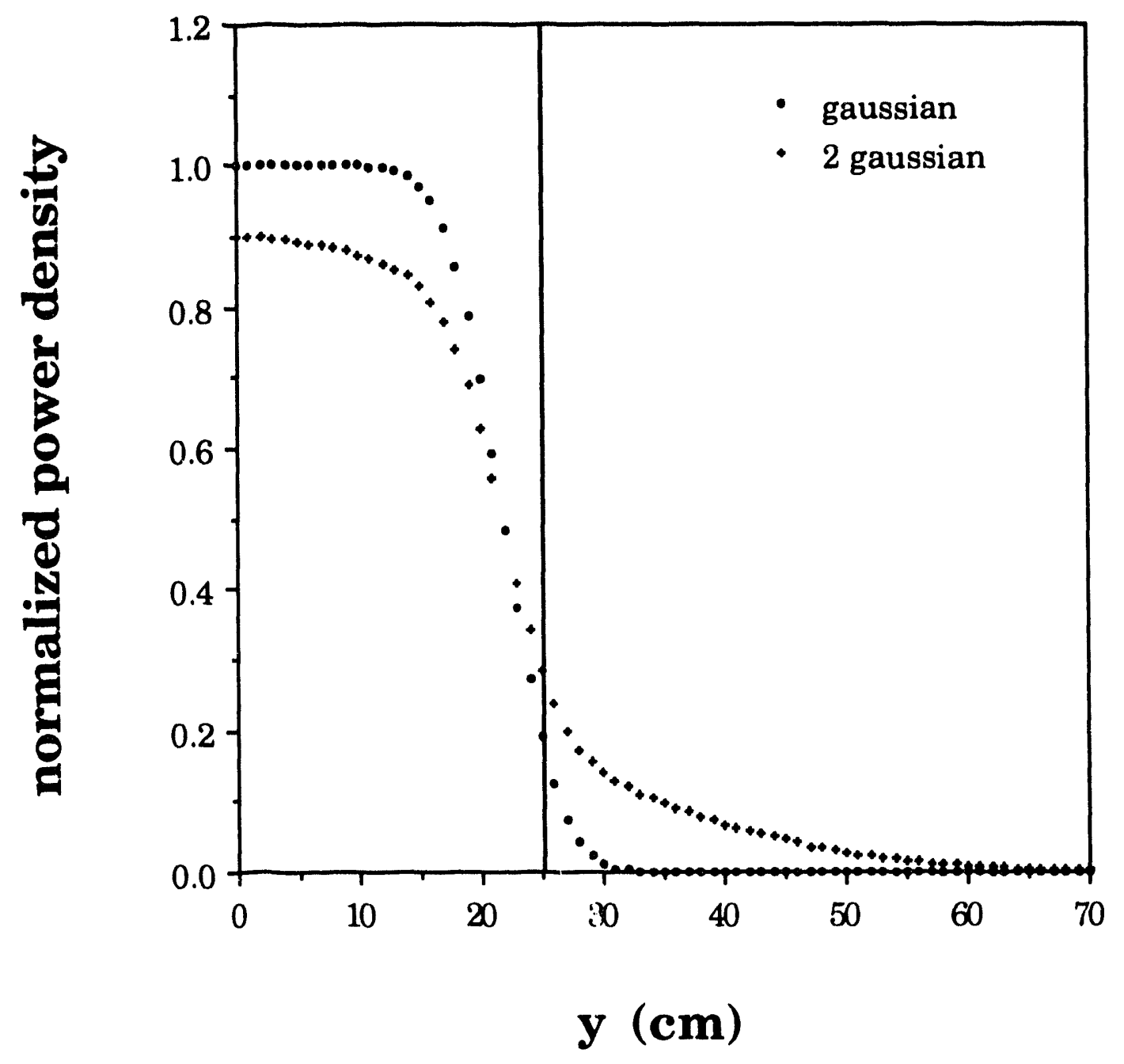

F19.8 


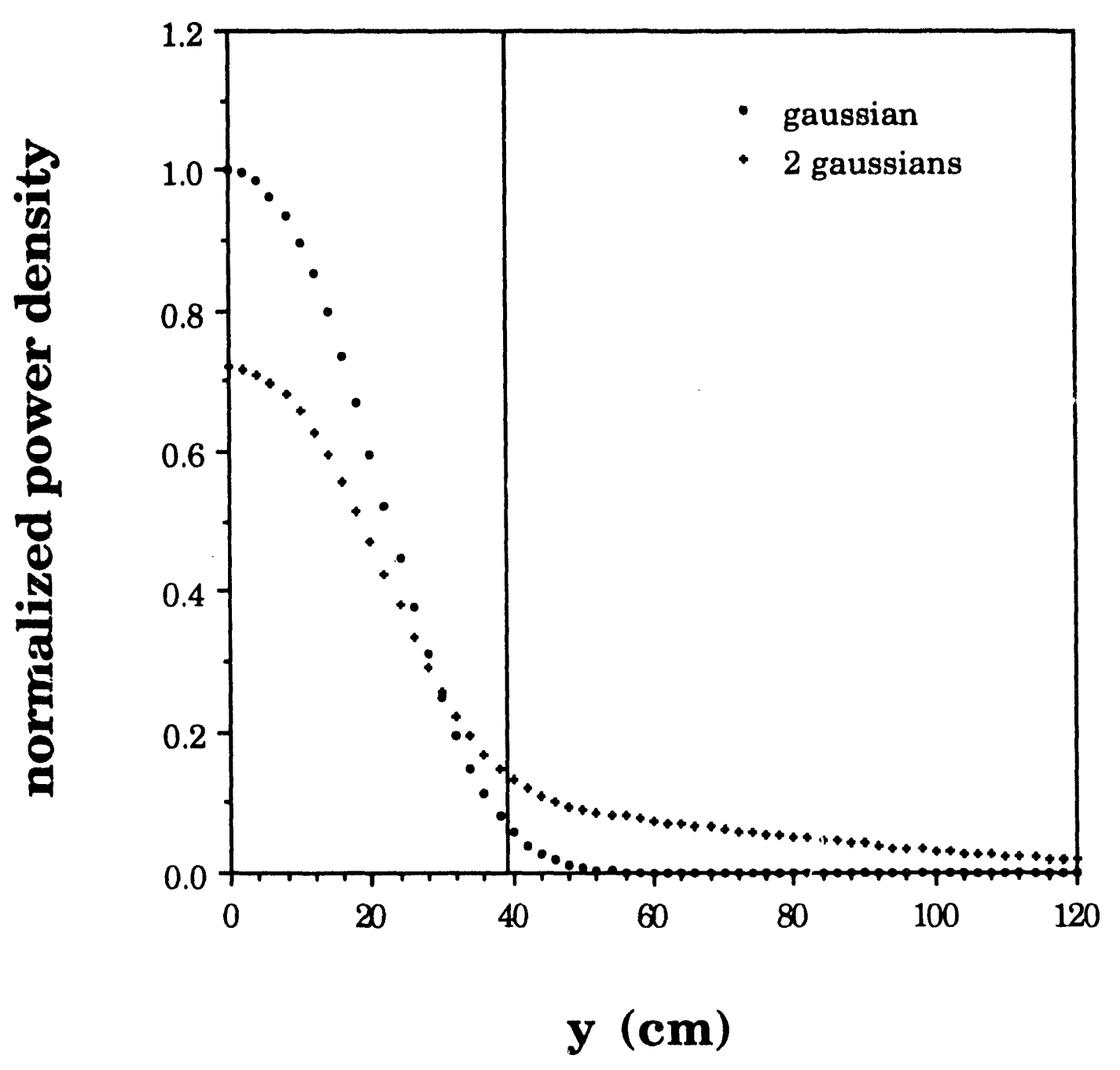

Fig. 9 


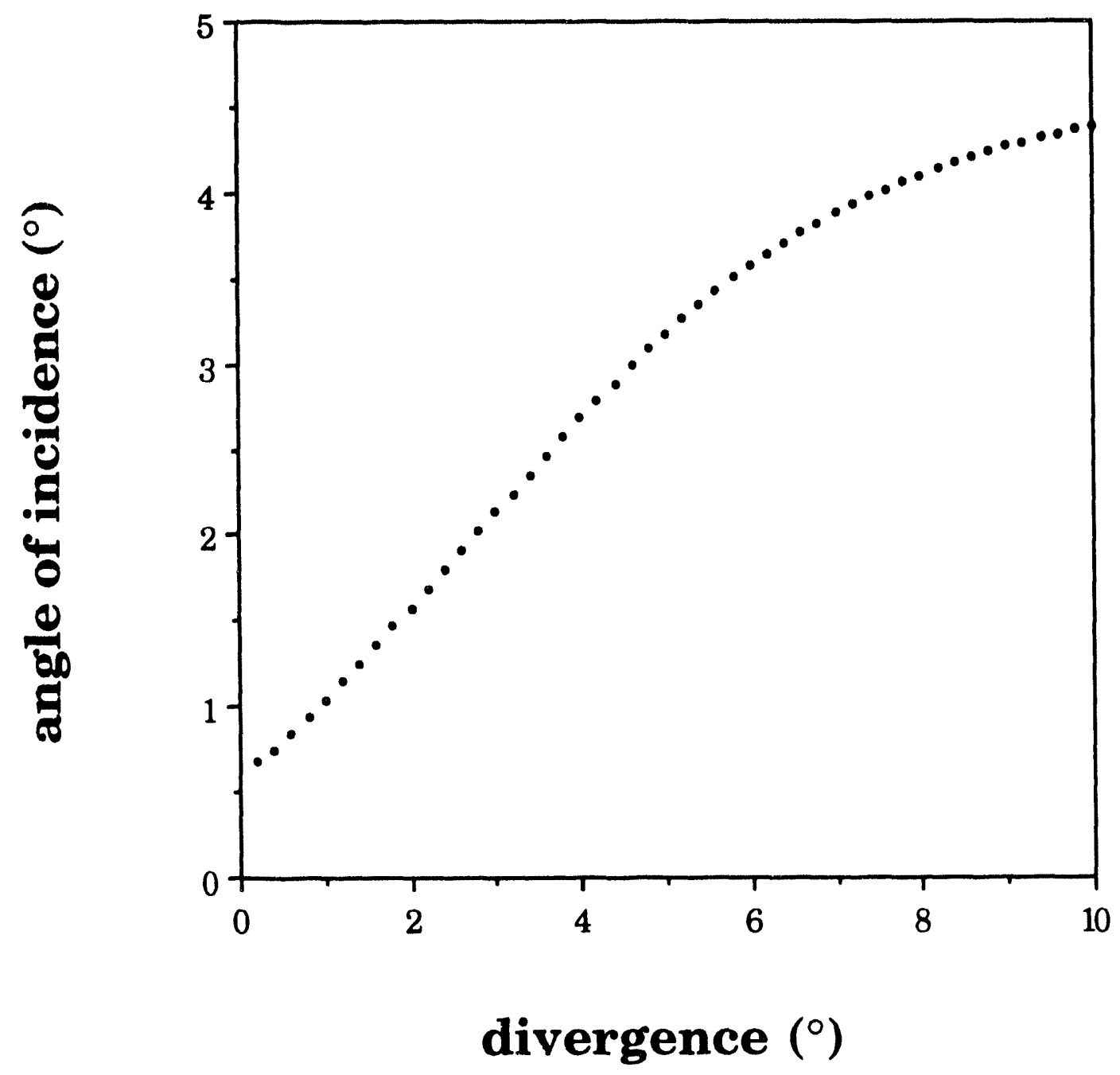

Fig. 10 


\section{EXTERNAL DISTRIBUTION IN ADDITION TO UC-420}

Dr. F. Paoloni, Univ. of Wollongong, AUSTRALIA

Prof. M.H. Brennan, Univ. of Sydney, AUSTRALIA

Plasma Research Lab., Australian Nat. Univ., AUSTRALIA

Prof. I.R. Jones, Flinders Univ, AUSTRALIA

Prof. F. Cap, Inst. for Theoretical Physics, AUSTRIA

Prof. M. Heindler, Institut fur Theoretische Physik, AUSTRIA

Prot. M. Goossens, Astronomisch Instituut, BELGIUM

Ecole Royale Militaire, Lab. de Phy. Plasmas, BELGIUM

Commission-European, DG. XII-Fusion Prog., BELGIUM

Prof. R. Bouciqué, Rijksuniversiteit Gent, BELGIUM

Dr. P.H. Sakanaka, Instituto Fisica, BRAZIL.

Prof. Dr. I.C. Nascimento, Instituto Fisica, Sao Paulo, BRAZIL Instituto Nacional De Pesquisas Espaciais-INPE, BRAZIL

Documents Office, Atomic Energy of Canada Lid., CANADA

Ms. M. Morin, CCFMTokamak de Varennes, CANADA

Dr. M.P. Bachynski, MPB Technologies, Inc., CANADA

Dr. H.M. Skarsgard, Univ. of Saskatchewan, CANADA

Prof. J. Teichmann, Univ. of Montreal, CANADA

Prof. S.R. Sreenivasan, Univ. of Calgary, CANADA

Prof. T.W. Johnston, INRS-Energie, CANADA

Dr. R. Bolton, Centre canadien de fusion magnétique, CANADA

Dr. C.R. James, Univ. of Alberta, CANADA

Dr. P. Lukác, Komenského Universzita, CZECHO-SLOVAKIA

The Librarian, Culham Laboratory, ENGLAND

Library, R61, Ruthertord Appleton Laboratory. ENGLAND

Mrs. S.A. Hutchinson, JET Library, ENGLAND

Dr. S.C. Sharma, Univ. of South Pacific, FIJI ISLANDS

P. Mähönen, Univ. of Heisinki, FINLAND

Prot. M.N. Bussac, Ecole Polytechnique., FRANCE

C. Mouttet, Lab. de Physique des Milieux lonisés, FRANCE

J. Radet, CEN/CADARACHE - Bat 506, FRANCE

Prof. E. Economou, Univ. of Crete, GREECE

Ms. C. Rinni, Univ. of loannina, GREECE

Preprint Library, Hungarian Academy of Sci., HUNGARY

Dr. B. DasGupta, Saha Inst. of Nuclear Physics, INDIA

Dr. P. Kaw, Inst. for Plasma Research, INDIA

Dr. P. Rosenau, Israel Inst. of Tochnology, ISRAEL Librarian, International Center for Theo Physics, ITALY Miss C. De Palo, Associazione EURATOM-ENEA , ITALY Dr. G. Grosso, Istituto di Fisica del Plasma, ITALY Prof. G. Rostangni, Istituto Gas Ionizzati Del Cnr, ITALY
Dr. H. Yamato. Toshiba Res \& Devel Center, JAPAN

Prof. I. Kawakami, Hiroshima Univ., JAPAN

Prof. K. Nishikawa, Hiroshima Univ., JAPAN

Librarian, Naka Fusion Research Establishment, JAERI, JAPAN

Director, Japan Atomic Energy Research Inst., JAPAN

Prol. S. Itoh, Kyushu Univ., JAPAN

Research Info. Crr., National Instit. for Fusion Saience, JAPAN

Prof. S. Tanaka, Kyoto Univ., JAPAN

Library, Kyoto Univ., JAPAN

Prof. N. Inove, Univ. of Tokyo, JAPAN

Secretary, Plasma Section, Electrotectnical Lab., JAPAN

S. Mori, Technical Advisor, JAERI, JAPAN

Dr. O. Mitarai, Kumamoto Inst. of Technology, JAPAN

Dr. G.S. Lee, Korea Basic Sci. Ctr., KOREA

J. Hyeon-Sook, Korea Atomic Energy Research Inst., KOREA

D.I. Choi, The Korea Adv. Inst. of Sci. \& Tech., KOREA

Prot. B.S. Liley, Univ. of Waikato, NEW ZEALAND

Inst of Physics, Chinese Acad Sci PEOPLE'S REP. OF CHINA

Library. Inst. of Plasma Physics. PEOPLE'S REP. OF CHINA

Tsinghua Univ. Library, PEOPLE'S REPUBLIC OF CHINA

Z. Li, S.W. Inst Physics, PEOPLE'S REPUBLIC OF CHINA

Prof. J.A.C. Cabral, Instituto Superior Tecnico, PORTUGAL

Prot. M.A. Hellberg, Univ. of Natal, S. AFRICA

Prof. D.E. Kim, Pohang Inst. of Sci. \& Tech., SO. KOREA

Prof. C.I.E.M.A.T, Fusion Division Library, SPAIN

Dr. L. Stenflo, Univ. of UMEA, SWEDEN

Library, Royal Inst. of Technology, SWEDEN

Prot. H. Wilhelmson, Chalmers Univ. of Tech., SWEDEN

Centre Phys. Des Plasmas, Ecole Polytech, SWITZERLAND

Bibliotheek, Inst. Voor Plasma-Fysica, THE NETHERLANDS

Asst. Prot. Dr. S. Cakir, Middle East Tech. Univ., TURKEY

Dr. V.A. Glukhikh,Sci. Res. Inst. Electrophys.I Apparatus, USSR

Dr. D.D. Ryutov, Siberian Branch of Academy of Sa., USSR

Dr. G.A. Eliseev, I.V. Kurchatov Inst., USSR

Librarian, The Ukr.SSR Academy of Sciences, USSR

Dr. L.M. Kovrizhnykh, Inst. of General Physics, USSR

Kernforschungsanlage GmbH, Zentralbibliothek, W. GERMANY

Bibliothek, Inst. Für Plasmaforschung, W. GERMANY

Prof. K. Schindler, Ruhr-Universitát Bochum, W. GERMANY

Dr. F. Wagner, (ASDEX), Max-Planck-Institut, W. GERMANY

Librarian, Max-Planck-Institut, W. GERMANY 

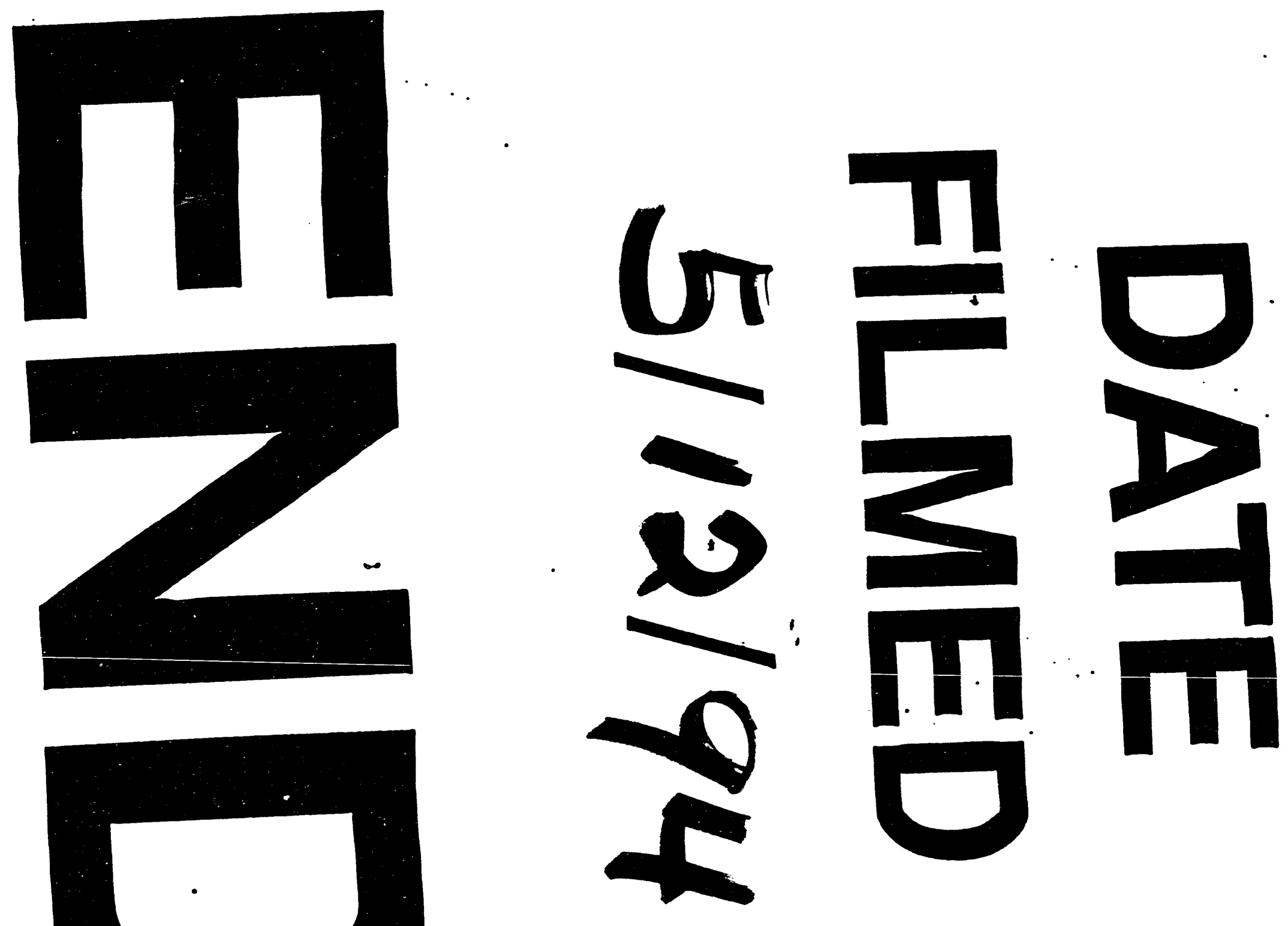
